\title{
In-situ Deposition of Ag Nanoparticles on Dopamine Pre-Modified Cotton Fabric and Analysis of Its Functional Mechanical and Dyeing Properties
}

Imana Tania ( $\square$ imanat008@gmai.com )

BUTEX

Mohammad Ali

BUTEX

Md. Shafiul Azam

BUET

Research Article

Keywords: Ag Nanoparticles, Dopamine, Cotton fabric, Functional property, Mechanical property

Posted Date: March 22nd, 2021

DOI: https://doi.org/10.21203/rs.3.rs-324700/v1

License: (c) (i) This work is licensed under a Creative Commons Attribution 4.0 International License.

Read Full License 


\section{Abstract}

This study investigates the potentiality of Ag nanoparticles for the preparation of value-added and improved functional textiles. It demonstrates the in-situ deposition of Ag nanoparticles on cotton fabric pre-functionalized by dopamine hydrochloride. Surface characterization of nano-Ag deposited fabric is done by SEM (scanning electron microscope) and EDS (energy dispersive spectroscopy) that confirms the shape and deposition of a higher amount of nano-Ag particles. The crystalline size and approximate shape are determined by X-ray diffraction spectroscopy. The results reveal that the nano-Ag deposition brings excellent performance on functional properties of cotton fabric. Antimicrobial activity is found as $82.60 \%$ reduction against $S$.aureus and $92 \%$ against E.coli measured by bacterial reduction rate $(\mathrm{R} \%)$. The fabric also shows good UV protection power and admirable crease resistance. The fabric has also been dyed with reactive dyestuff and enhanced dyeing performance is found due to nano-Ag deposition. However, nano deposition causes a slight change in some important mechanical properties.

\section{Introduction}

The textile industry is benefited by using the attributes of nanoparticles in different ways. For textile product advancement, the contribution of the nanoparticle is undeniable [1]. The different types of nanoparticle use in the textile sector in different ways got prospered. The notable instances are the development of desire textile characteristics, modify the physical, chemical, and biological properties of textile, engineered, synthesized, and altered the conventional materials and process to develop future generation improved materials, devices, systems, and structures [2,3]. To achieve the mentioned property, effective and relevant nanoparticle deposition on the textile surface is one of the main ways. Some nanoparticles have felicitated for their groundbreaking contribution to growing functional textiles. Among them, silver nanoparticles are traditional and superior for its huge benefit as antimicrobial as well as antiviral perspective $[4,5]$. Besides silver nanoparticle is drawing remarkable attention in research and commercial field due to its strong action towards a broad range of microorganisms, lower toxicity to human, high selectivity, durability, improved dye-ability, and biocompatibility [6,7]. Textile researchers have reported the great achievement of antimicrobial textiles using silver nanoparticles [8-10]. Direct coating or in-situ immobilizations are the two main ways of nanoparticle deposition on fabrics surface. Nevertheless, the direct coating might have discontinuity problems, less durable, aggregation of additives, low affectivity [11]. Conversely, in-situ deposition overcomes those problems and even ensures intensive affixation, reduces wastage of particles, and improved durability.

However, the silver nanoparticle has no abundant attraction, deposition, and affixation power towards fabric, so an additional adhesive or fixing agent is required to immobilize the particle into the fabric. So auxiliaries are mostly used in the direct coating by pad dry and cure method. The improper selection of adhesive material may lead to the durability and effectivity problem of nano-treated fabric. Instead of using adhesive coating material, a good option is fiber surface modification to enhance the attraction and improve the fixation of nanoparticles. Different ways are available to modify the textile surface for better performance of nanoparticle deposition. Fiber modification in the case of in-situ nano deposition also 
offers a greater opportunity for instant fixation [12]. In this research, the fabric is modified chemically by using dopamine hydrochloride. In literature, it has been found that dopamine is an excellent substance capable to be self-polymerized and makes a film on material surface and creates covalent or non-covalent bonds with organic or inorganic materials $[13,14]$. As it has strong adhesive property improves surface performance and firmly affixes the nanometal on the textile surface.

However, cotton is the most popular natural fiber in the world. Its consumption is higher than the other natural fibers owing to its comfortability, biodegradability, dyeability, etc. Nevertheless, the fibers are more prone to bacterial growth and tend to crease formation. Therefore, nanoparticle treatment can overcome the problem and make the cotton more attractive and functional in use. Thus, the present study focuses on

the deposition of nanoparticles on cotton fabric to make it a more valuable and advance textile to keep the modern market.

Here, the nano-Ag is deposited on dopamine modified cotton fabric to obtain multifunctional property. Silver nano formation and deposition have been made to get the benefits of self-polymerization and reduction power of dopamine hydrochloride. Other researchers have explored its unique quality and feature, and have gotten it as an exceptional material for surface modification with the reduction power. Lui et al. 2016 [15] make silver plating on cotton fiber by dopamine modification and analyzed the surface resistivity and found a high electric conductive cotton surface. Dopamine is also used in the formation of sericin-based composite film to incorporate the silver in nano form[16]. The manmade fiberis also modified by using dopamine. For instance Kuang, X.H et al. 2017 [17] used polydopamine to make surface functionalization for developing hydrophilic and antistatic surfaces. Further, it is also found to be used in polyester and silk fire for in-situ deposition of Ag nanoparticles [18,19]. Those works are the inspiration and encouragement of the present study. Here a convenient and easy way is followed to make a dopamine solution and fabric modification. Since no study was found about the crease-resistance, UV protection power, dyeing performance, mechanical properties of Ag nano deposited fabric on dopamine-modified cotton. The dyeing performance study will accelerate the use of dopamine pre-modification for dyed cloth and disclose its other performances. Therefore, current study will reveal all mentioned functional properties along with the investigation on mechanical performances and finally brings one-step ahead for inventing advanced value-added textile.

\section{Experimental Section}

\subsection{Materials}

Scoured and bleached $100 \%$ cotton fabric of plain weave structure is used for this experiment. The woven fabric consists of 80 ends per inch (EPI), 75 picks per inch (PPI), and 168 GSM (gram per square meter). The chemicals: dopamine hydrochloride, silver nitrate, hydroxymethyl aminomethane, and $\mathrm{HCl}$ are purchased as the analytical grade from Sigma Aldrich Germany. Two dyestuffs are used for dyeing, Reactobond Red 2GX (Cl: Red 194) and Reactobond Blue BRX (Cl: Blue 221) are collected from Meghmani Dyes and Intermediates Ltd., Ahmedabad, India. Deionized water is used throughout the experiment. 


\subsection{In-situ deposition of nano-Ag}

In-situ generation of silver nanoparticles on the cellulose fabric with the aid of dopamine hydrochloride is shown in Fig.1. The figure designates the dopamine-cellulose formation with a chemical structure that refers to the pre-functionalization of cotton fabric. Firstly the buffer solution is prepared by hydroxyethyl ammonium base. Afterward, a $10 \mathrm{mM}$ of dopamine solution is dissolved in the tris buffer. The $\mathrm{p}^{\mathrm{H}}$ of the solution is maintained at 8.5 with diluted hydrochloric acid. Later than 24 hours of immersion along with stirring makes a coated fabric named dopamine-cellulose of blackish shade as shown in Fig.2 (b). Subsequently, the dopamine functionalized cotton is kept for eight hours in silver nitrate salt. It can be noted that dopamine is an agent that makes silver into nano form and fixes the nanoparticle into the fabric surface directly using its adhesive property. So the prepared nanoparticle gets a media for instant deposition. Finally, the fabric is placed in a vacuum oven for twelve hours. The nano-Ag deposited fabric is shown in Fig.2(c). Untreated fabric is shown in Fig.2 (a). The color difference of untreated fabric, dopamine-modified cotton fabric and nano Ag deposited fabric (D.NanoAg) fabric are shown in Table 1. The color coordinates $L^{*}, a^{*}$, and $b^{*}$ and color difference DE in Table 1 indicate that the Ag nanoparticles deposition make the fabric darker than the untreated fabric. The color strength (K/S) and reflectance value specify that the treated fabric is blackish in color.

Table 1. CIE L*a*b* color difference and color strength value of untreated and treated fabric

\begin{tabular}{|lllllll|}
\hline Samples & $\mathrm{L}^{*}$ & $\mathbf{a}^{*}$ & $\mathbf{b}^{*}$ & $\mathrm{DE}$ & $\mathrm{K} / \mathrm{S}$ & $\mathbf{R} \%$ \\
\hline Untreated & 92.25 & -0.47 & 3.80 & - & 0.67 & 84.38 \\
\hline Dopamine-cotton & 58.83 & 4.32 & 13.49 & 35.14 & 2.21 & 40.03 \\
\hline Dopa+.NanoAg & 49.53 & 5.58 & 13.48 & 43.98 & 3.62 & 29.09 \\
\hline
\end{tabular}

\subsection{Measurement and Analysis}

\subsubsection{Characterization of the treated fabric}

The surface morphology of nano-Ag deposited fabric is characterized by SEM: scanning electron microscopy, EDS: energy dispersive spectroscopy (EDS), and XRD analysis. The JSM -6700F, Tokyo, Japan is used for SEM and EDS analysis. X-Ray Diffractometer from Phillips, Expert Pro, of Holland is used for XRD (x-ray diffraction) analysis.

\subsubsection{Functional property analysis}

Three important functional properties such as antimicrobial activity, UV (ultra-violet) protection, and crease resistance are investigated. Standard test methods ASTM E2149 - 01 is used for antibacterial analysis and expressed by bacterial reduction percentage. The following equation (Eq-1) is used to calculate the reduction $\%$ of bacteria after nano-Ag deposition on the fabric surface. 


\section{Bacterial reduction percentage $(R \%)=\frac{N o-N t}{N o} \times 100$}

Where $N_{o}=$ number of colonies in untreated and $N_{t}=$ number of colonies after 1 hour of introducing samples.

The UV protection of treated and untreated fabric has been measured by PerkinElmer UV visible machine from the USA and expressed by transmittance percentage of incident solar light of wavelength 220-700nm [20]. The transmittance curve of incident light has been analyzed by dividing the following three regions namely A, B and C of the solar spectrum, i) UV-A of wavelength: $320-400 \mathrm{~nm}$, ii) UV-B of $280-320 \mathrm{~nm}$, and iii) UV-C of $200-280 \mathrm{~nm}$.

Fabric crease resistance is generally measured by the recovery angle of fabric after creasing. The more angle of recovery indicates more resistance. It is a quantitative measurement of the easy-care property of the fabric. In the current research, the crease recovery angle of untreated and treated fabric is measured by AATCC (The American Association of Textile Chemists and Colorists) standard test method [21].

\subsubsection{Dyeing performance analysis}

To investigate the dyeing performance, samples have been dyed by red and blue color of reactive dye (1\% shade) following the procedure used by Simu et al. [17]. To represent the dyeing performance, color strength, dye exhaustion, fixation, and colorfastness has been measured and evaluated. That color performance is determined by the spectrophotometer of the data color series-600+. The kubelka Munk theory expressed by Eq-2 is followed to calculate color strength (K/S) [18]. Dye exhaustion percentage is measured by Eq-3 and fixation\% is determined by Eq-4. Colorfastness is assessed by standard ISO105CO3 for wash, IS0105X12 for rubbing, and IS0105B02 is for light.

$\mathrm{K} / \mathrm{S}$ (Color strength) $=\left[\left\{(1-\mathrm{R})^{2} / 2 \mathrm{R}\right\}\right]$

Where $\mathrm{R}$ is the reflectance, $\mathrm{K}$ is the absorbance coefficient and $\mathrm{S}$ is the scattering coefficient.

Exhaustion \% $=(\mathrm{Co}-\mathrm{Cs}) / \mathrm{Co} \times 100$

Co $=$ initial concentration of dye in dye bath, $\mathrm{Cs}=$ concentration during the process

Fixation\% = Exhaustion\% - (washing + soaping + other) loss.

\subsubsection{Mechanical property analysis}

For analysis of the mechanical property, tensile strength, elongation, tearing strength, bending length, frictional coefficient, are considered to investigate. The tensile strength test is measured by method 13934$1: 2013$, and tearing strength is measured byIS013937-2:2000. Titan universal strength tester of Jeams Heals is used for strength measurement. Fabric stiffness expressed by bending length is determined by ASTM D1388 using Shirley stiffness tester. Martindale abrasion and pilling tester of SDL International, 
England, determines abrasion resistances followed by ISO 12947 and pilling resistance followed by ISO 12945-2.

All experimental samples are conditioned in the standard atmosphere at $20 \pm 5^{\circ} \mathrm{C}$ and $65 \pm 2 \%$ relative humidity for 12 hours in a conditioning lab before every test.

\section{Results And Discussion}

\subsection{Characterization of fabric}

The surface morphology of untreated and Ag deposited fabric is characterized by SEM analysis and shown in Fig.3. The figure shows an enormous deposition of nano-Ag on dopamine modified fabric. Figure 3 (a) shows the untreated fabric where no Ag nanoparticle exists. It can be noted that this method shows more deposition of Ag nanoparticles than that of other in-situ deposition methods of our previous work $[12,22]$. By initial observation, SEM image proves the successful immobilization of Ag nanoparticles into the cotton fabric surface. It designates that dopamine modification is a better choice for nano-Ag formation and deposition as it is capable to deposit more amount of nano-Ag. Hence the treated fabric surface shows a uniform coverage of nano-Ag with size apparently $90 \mathrm{~nm}$ found from a size measuring software as in Fig. 3(b). The EDS curve shows the elemental mass composition of fabrics. The untreated fabric as in Fig. 3(c) shows the presence of carbon and oxygen i.e. the basic element of cellulose. In contrast, a particular point of Ag immobilized fabric gives 2.1\% Ag nanoparticle along with carbon and oxygen as shown in Table-2. Another important characterization is XDR, which is shown in Fig.4. This XRD curve reveals the crystalline shape and average size of the obtained nanosilver. The peaks of the XRD pattern indicate the obvious formation of Ag nanoparticle Analyzing its corresponding peaks and using the Bragg's equation as Eq-4 the size of nano-Ag has found $60 \mathrm{~nm}$ The measurement is carried out at a scanning rate of 8 degrees/min in $2 \theta$ range of $20-80$.

Particle Size $=(0.9 \times \lambda) /(d \cos \theta)(4)$

Where, $\lambda=1.54060 \AA, 0.9 \times \lambda=1.38654, \theta=2 \theta / 2, d=$ the full width at the half maximum intensity of the peak.

The sharp peaks of the XRD pattern are obtained at $2 \theta=38.8^{\circ}, 45.5^{\circ}, 50.98^{\circ}, 64.9^{\circ}, 56.52^{\circ}, 72.49^{\circ}$, and $78.07^{\circ}$ which designates the obvious formation of crystalline silver nanoparticles. Literature study also found similar peaks for Ag nanoparticles obtain by different synthesis processes $[23,24]$.

Table 2. Elemental mass composition of untreated and nano-Ag deposited fabric 


\begin{tabular}{|llllll|}
\hline sample & \multicolumn{5}{|c|}{ Elemental composition (mass \%) } \\
\cline { 2 - 6 } & $\mathbf{C}$ & $\mathbf{N}$ & $\mathbf{0}$ & $\mathbf{C l}$ & $\mathrm{Ag}$ \\
\hline Untreated & 51.37 & 48.63 & 0 & 0 & 0 \\
\hline D. Nano Ag & 48.34 & 6.01 & 43.37 & 0.18 & 2.1 \\
\hline
\end{tabular}

\subsection{Functional property analysis}

\subsubsection{Antibacterial activity}

The antimicrobial activity expressed by bacterial growth reduction percentages obtained is shown in Fig. 5 (a-d). The figure represents the number of bacteria existing due to the action of untreated and nano-Ag immobilized fabric. It is found that a considerable amount of bacteria is reduced due to the action of $\mathrm{Ag}$ deposited fabric. So the bacterial growth of both gram-positive and gram-negative bacteria is lower on the disk plate of Ag nano treated fabric as in Fig. 5(b,d) compared with the untreated fabric in Fig. 5(a,c). Quantitatively, the bacterial reduction percentage for untreated and treated fabric for both bacteria is shown in Table 3. The table indicates the excellent antimicrobial activity of nano-Ag deposited fabric that is around $86 \%$ for S.aureus and $93 \%$ for E.coli. It can be pointed out that this process of Ag nano deposition is more effective for the reduction of E.coli bacteria. The reason behind the admirable antimicrobial activity could be the contribution of uniform and much depositions of nano-Ag on the fabric surface with the modification of dopamine.

Table 3. Bacterial reduction percentage of untreated and treated fabric against S.aureus and E.coli

\begin{tabular}{|c|c|c|c|c|c|c|}
\hline \multirow[t]{2}{*}{ Sample } & \multicolumn{3}{|c|}{ Staphylococcus aureus } & \multicolumn{3}{|l|}{ Escherichia coli } \\
\hline & $\begin{array}{l}\text { Surviving } \\
\text { cells } \\
\text { (CFU/ml)after } \\
0 \text { contact } \\
\text { time }\end{array}$ & $\begin{array}{l}\text { Surviving } \\
\text { cells } \\
\text { (CFU/ml) } \\
\text { after } 1 \\
\text { hour }\end{array}$ & $\begin{array}{l}\text { Bacterial } \\
\text { reduction } \\
\text { (R\%) after } \\
1.0 \text { hour }\end{array}$ & $\begin{array}{l}\text { Surviving } \\
\text { cells } \\
\text { (CFU/ml)after } \\
0 \text { contact } \\
\text { time }\end{array}$ & $\begin{array}{l}\text { Surviving } \\
\text { cells } \\
\text { (CFU/ml)after } \\
1.0 \text { hour } \\
\text { contact time }\end{array}$ & $\begin{array}{l}\text { Bacterial } \\
\text { reduction } \\
(\mathrm{R} \%) \text { after } \\
1.0 \text { hour }\end{array}$ \\
\hline Untreated & -- & - & -- & - & - & - \\
\hline $\begin{array}{l}\text { D. Nano } \\
\text { Ag }\end{array}$ & $1.45 \times 10^{5}$ & $2.00 \times 10^{4}$ & 86.20 & $6.44 \times 10^{5}$ & $4.1 \times 10^{5}$ & 93.63 \\
\hline
\end{tabular}

\subsubsection{UV blocking property (Ultraviolet protection)}

The obtained results of the transmittance value of untreated and treated fabrics are placed in Fig.6. The average transmittance for different wavelengths is also shown in Table 4. From the figure and table, it is found that the nano deposited fabric imparts excelent UV protection ability of the fabric as the sample D.NanoAg shows $12 \%$ transmittance in UV-A region and $11-12 \%$ in the UV-B region. This is a lower transmission than untreated fabric. The less transmittance percentage means more blockage of UV rays and higher UV protection. It indicates that due to silver nanoparticle deposition the fabric will block around 
$90 \%$ UV rays. Thus the treated fabric produced by nano-Ag deposition is able to protect the user from harmful effects of UV rays and reduce the sub burns and other skin diseases. Yet the existence of inherence UV protection power of silver nanoparticle is not found in the literature, the reason for UV blockage might be the blackish color of the nano-Ag immobilized fabric. It can be observed from images in Fig. 2(c) that the dopamine pre-functionalization and further nano deposition make the fabric more blackish. It is known that the black color has an added tendency to absorb the solar light and not permitted to transmit the whole incident light.

\section{Table 4. Average UV Transmittance percentage of different wavelength}

\begin{tabular}{|llll|}
\hline Sample & \multicolumn{2}{l|}{ Transmittance (\%) } & \\
\cline { 2 - 4 } & UV-A (320-400) nm & UV-B (280-320) nm & UV-C (200-280) nm \\
\hline Untreated & 88 & $90-89$ & 90 \\
\hline D.Nano Ag & 12 & $10-11$ & 10 \\
\hline
\end{tabular}

\subsubsection{Crease resistance}

The crease resistance of untreated and the nano-Ag deposited fabrics (D.Nano Ag) are determined by crease recovery angle in degrees as shown in Fig.7. The figure demonstrates that the nano-Ag deposition increases the crease resistance power of fabric at around $5 \%$. The crease resistance is the expression of the easy-care property of the fabric. It is also related to the serviceability of fabric. The obtained results confirm that the nano deposition in this way imparts an additional quality of improving crease resistance of cotton fabric. The crease formation happens on the cotton fabric due to the re-bonding of the free hydroxyl group present in the cellulose structure [25]. When the cotton fiber is modified with dopamine hydrochloride then some of its fee hydroxyl groups take part in chemical bonding. Besides, the nano-Ag also deposits into the fiber interior and lessens the fabric free area or amorphousness. If the fabric does not get enough space for re-bonding, and the free- $\mathrm{OH}$ group participates in bonding then fabric will be more prone to come back to its original position after distortion by the action of external forces. Consequently, the crease resistance will improve.

\subsection{Dyeing performance}

The dyeing performance of the treated and untreated fabric is expressed in terms of color strength, dye exhaustion, fixation, and colorfastness measurement. Here two reactive dyestuff of red and blue is used for dyeing and the obtained results of the mentioned points are presented in Table 5 and Table 6 . The table represents that the overall dyeing performance of treated fabric increases due to Ag deposition. In the performance study, the Ag modification brings around $12 \%$ improvement of color strength, around $3 \%$ dye exhaustion, and $2.4 \%$ of dye fixation for red dyestuff. The blue color also shows an improvement of color strength, dye exhaustion, and dye fixation. The overall colorfastness of treated fabric is also satisfactory for both red and blue dyestuff. The reason behind the improvement of dyeing performance is the mordanting power of Ag nanoparticles that ensures to grip more dyestuffs on fabric surface that causing 
increased color depth. Our previous work also revealed the improvement of color performance of cotton fabric where Ag nano was deposited by in-situ method on alkali pre-modified fabric[22]. Since all color performance increases, this treatment has also a positive influence on the dyeing performance of the cotton fabric. From the analysis, it is found that Ag deposition can make the fabric antibacterial, UV protective, crease-resistive, and high-performance dyed textiles. It can be noted that this treatment has no adverse effect on shade stability. Eventually, the study indicates an optimistic impact of dopamine polymer on the reactive dyed cotton fabric.

Table 5. Color strength, dye exhaustion, and dye fixation of untreated and nano-Ag deposited fabric (D.Nano Ag)

\begin{tabular}{|lllllll|}
\hline Sample & Reactive Red & \multicolumn{5}{c|}{ Reactive Blue } \\
\cline { 2 - 6 } & $\begin{array}{l}\text { Color } \\
\text { strength(K/S) }\end{array}$ & $\begin{array}{l}\text { Dye } \\
\text { exhaustion } \\
(\%)\end{array}$ & $\begin{array}{l}\text { Dye } \\
\text { Fixation } \\
\%\end{array}$ & $\begin{array}{l}\text { Color } \\
\text { strength(K/S) }\end{array}$ & $\begin{array}{l}\text { Dye } \\
\text { exhaustion }\end{array}$ & $\begin{array}{l}\text { Color } \\
\text { strength(K/S) }\end{array}$ \\
\hline Untreated & 10.09 & 79.65 & 78.22 & 2.78 & 78.15 & 77.54 \\
\hline D.NanoAg & 11.28 & 81.79 & 80.10 & 5.25 & 81.33 & 80.12 \\
\hline
\end{tabular}

Table 6. Colorfastness of untreated and treated fabric for two dyestuffs

\begin{tabular}{|c|c|c|c|c|c|c|c|c|c|}
\hline \multirow[t]{3}{*}{ Dyestuff } & \multirow[t]{3}{*}{ Sample } & \multicolumn{3}{|c|}{ Colorfastness to wash } & \multicolumn{2}{|c|}{$\begin{array}{l}\text { Colorfastness } \\
\text { to rubbing }\end{array}$} & \multicolumn{2}{|c|}{$\begin{array}{l}\text { Colorfastness } \\
\text { to perspiration }\end{array}$} & \multirow{3}{*}{$\begin{array}{l}\text { Color } \\
\text { fastness } \\
\text { to light }\end{array}$} \\
\hline & & \multirow{2}{*}{$\begin{array}{l}\text { Shade } \\
\text { change }\end{array}$} & \multicolumn{2}{|c|}{ Staining } & \multirow[t]{2}{*}{ Dry } & \multirow[t]{2}{*}{ Wet } & \multirow[t]{2}{*}{ Alkaline } & \multirow[t]{2}{*}{ Acid } & \\
\hline & & & Cotton & Viscose & & & & & \\
\hline \multirow{2}{*}{$\begin{array}{l}\text { Reactive } \\
\text { red }\end{array}$} & Untreated & $4-5$ & 4 & 4 & $3-4$ & 3 & 4 & 4 & 4 \\
\hline & D.NanoAg & $4-5$ & $4-5$ & $4-5$ & $3-4$ & $3-4$ & $4-5$ & $4-5$ & $4-5$ \\
\hline \multirow{2}{*}{$\begin{array}{l}\text { Reactive } \\
\text { Blue }\end{array}$} & Untreated & 4 & 4 & 4 & 3 & 3 & 4 & 4 & 4 \\
\hline & D.NanoAg & $4-5$ & 4 & 4 & 3-4 & 3 & 4 & 4 & 4 \\
\hline
\end{tabular}

\subsection{Mechanical properties}

The important mechanical properties of nano-Ag immobilized fabric compared with untreated fabric are shown in Table 7. Little changes are found in tensile strength, tearing strength, and elongation for dopamine-nano treated fabric. The bending length is found a bit higher because the metallic nanoparticle goes to the fiber interior and imparts stiffness. The frictional resistance is quite similar for treated and untreated fabric. Our Previous work of in-situ immobilized Ag reported much reduction of strength, where the fabric was pre functionalized by alkali $(\mathrm{NaOH})$ [12]. In that case, the caustic modification harmed the main cellulose structure. Due to the cellulosic polymer degradation, a decrease in strength was found. 
Nevertheless, this work deals with dopamine pre-functionalization of cotton and found competitively better results than before. Therefore, dopamine functionalization has no bad impact on cellulose structure. However, the mechanical property is one of the important criteria and determines the durability and serviceability of textile goods. Besides, nano deposition in this way reduce the degradation of mechanical properties compared with other in-situ deposition [26].

Table 7. Mechanical properties of untreated and nano-Ag deposited fabric

\begin{tabular}{|c|c|c|c|c|c|c|c|c|c|}
\hline \multirow[t]{2}{*}{ Sample } & \multicolumn{2}{|c|}{$\begin{array}{l}\text { Tensile strength } \\
(\mathrm{N})\end{array}$} & \multicolumn{2}{|c|}{ Elongation (\%) } & \multicolumn{2}{|c|}{$\begin{array}{l}\text { Tearing } \\
\text { strength }(\mathrm{N})\end{array}$} & \multirow[t]{2}{*}{$\begin{array}{l}\text { Bending } \\
\text { length }(\mathrm{cm})\end{array}$} & \multicolumn{2}{|c|}{$\begin{array}{l}\text { Frictional } \\
\text { resistant }\end{array}$} \\
\hline & Warp & Weft & Warp & Weft & Warp & Weft & & Static & Kinetic \\
\hline Untreated & 730.52 & 572.60 & 21.10 & 14.75 & 9.11 & 4.3 & 1.8 & 0.35 & 0.32 \\
\hline D.NanoAg & 728.26 & 561.31 & 21.0 & 13.5 & 8.56 & 4.0 & 2.1 & 0.33 & 0.30 \\
\hline
\end{tabular}

\section{Conclusions}

The current study reveals the effects of Ag nanoparticles on cotton fabric pre-functionalized by dopamine hydrochloride regarding functional, mechanical, and dyeing properties. The formation and deposition of nanoparticles are confirmed by the SEM images. The EDS analysis explores the elemental mass composition of untreated and nano-Ag treated fabric. XRD proves the particle size and crystalline shape of silver nanoparticles. The results exhibit around $86 \%$ reduction of S.aureus bacteria and around $93 \%$ of E.coli compare with untreated fabric. The UV protection of Ag deposited fabric is also good. Nano silver deposition by the current process causes better crease resistance and improved dyeing performance than untreated fabric. This method slightly alters the mechanical properties of nano-Ag deposited fabric. The improvement of the physical and mechanical properties of nano-Ag deposited fabric by the in-situ method might be the new research area of textile researchers. However, the Ag nanoparticles immobilization has been produced a functional as well as valuable textile cotton fabric, having excellent antimicrobial activity, good UV protection property, better dyeing performance, and crease resistance.

\section{Declarations}

\section{Acknowledgments}

The authors like to express their cordial thanks and gratitude to the Mechanical engineering department of BUET for supporting to do the experimental work. We are also thankful to Glass and Ceramics Engineering, and Biomedical Engineering department of BUET for characterization analysis and antibacterial test. Special thank goes to the ministry of science and education, Bangladesh for the financial support under "NST fellowship".

\section{Disclosure statement}


The authors declare that they have no conflict of interest.

\section{References}

[1] P.J. Rivero, A. Urrutia, J. Goicoechea, F.J. Arregui, Nanomaterials for Functional Textiles and Fibers, Nanoscale Res. Lett. (2015). https://doi.org/10.1186/s11671-015-1195-6.

[2] S. Witharana, C. Hodges, D. Xu, X. Lai, Y. Ding, Aggregation and settling in aqueous polydisperse alumina nanoparticle suspensions, J. Nanoparticle Res. (2012). https://doi.org/10.1007/s11051-0120851-3.

[3] K. PATRA, Application of nanotechnology in textile engineering: An overview, J. Eng. Technol. Res. (2013). https://doi.org/10.5897/jetr2013.0309.

[4] M. Asadullah Jahangir, S. Sarim Imam, A. Muheem, Y. K, Silver Nanoparticles: The Good ,The Bad and The Future Research and Reviews, J. Pharm. Nanotechnol. 4 (2016) 1-10.

[5] K.K. Bamzai, G. Kour, B. Kaur, S.D. Kulkarni, Synthesis of Silver Nanoparticles through Chemical Reduction and its Antibacterial Effect, J. Magn. Magn. Mater. 327 (2013) 159-166. http://dx.doi.org/10.1016/j.jmmm.2012.09.013.

[6] Shahid-UI-Islam, B.S. Butola, F. Mohammad, Silver nanomaterials as future colorants and potential antimicrobial agents for natural and synthetic textile materials, RSC Adv. (2016). https://doi.org/10.1039/c6ra05799c.

[7] M. Radetić, Functionalization of textile materials with silver nanoparticles, J. Mater. Sci. (2013). https://doi.org/10.1007/s10853-012-6677-7.

[8] F. Zhang, X. Wu, Y. Chen, H. Lin, Application of silver nanoparticles to cotton fabric as an antibacterial textile finish, Fibers Polym. (2009). https://doi.org/10.1007/s12221-009-0496-8.

[9] N.R. Ghosh, S., S. Yadav, Antibacterial properties of cotton fabric treated with silver nanoparticles, J. Text. Inst. 101 (2010) 917-924.

[10] Tania, Imana Shahrin, Ali, Mohammad, Islam, Zahidul, Solaiman, Development of antimicrobial activity and mechanical performances of cotton fabric treated with silver nano particles (AgNPs), in: AIP Conf. Proc. 2121, 2019: p. 15003. https://doi.org/10.1063/1.5115968.

[11] T. Jiang, L. Liu, J. Yao, In situ deposition of silver nanoparticles on the cotton fabrics, Fibers Polym. 12 (2011) 620-625. https://doi.org/10.1007/s12221-011-0620-4.

[12] I.S. Tania, M. Ali, M.S. Azam, In-situ synthesis and characterization of silver nanoparticle decorated cotton knitted fabric for antibacterial activity and improved dyeing performance, SN Appl. Sci. 1 (2019) 19. https://doi.org/10.1007/s42452-018-0068-x. 
[13] Y. Xu, X., Bai, B., Ding, C., Wang, H., \& Suo, Synthesis and properties of an ecofriendly superabsorbent composite by grafting the poly (acrylic acid) onto the surface of dopamine-coated sea buckthorn branches., Ind. Eng. Chem. Res. . 54 (2015) 3268-3278.

[14] S. Chen, L. Zhang, M. Sun, X. Zhang, W. Chen, Surface modification of polypropylene nonwoven fabrics by grafting of polydopamine, Adv. Polym. Technol. (2018). https://doi.org/10.1002/adv.22136.

[15] Liu, H., Zhu, L., Xue, J., Hao, L., Li, J., He, Y. and Cheng, B., A novel two-step method for fabricating silver plating cotton fabrics. 2016., J. Nanomater. (2016).

[16] Y. Cai, R., Tao, G., He, H., Song, K., Zuo, H., Jiang, W. and Wang, One-step synthesis of silver nanoparticles on polydopamine-coated sericin/polyvinyl alcohol composite films for potential antimicrobial applications. Molecules, .. Mol. 22 (2017) 721.

[17] Kuang, X.H., Guan, J.P., Tang, R.C. and Chen, G.Q., Surface functionalization of polyamide fiber via dopamine polymerization. Materials No Title, Mater. Res. Express. 4 (2017) 095302.

[18] G.Q. Kuang, X.H., Guan, J.P., Chen, W., Tang, R.C. and Cheng, Coloration and functional modification of silk fiber via dopamine polymerization. In 2017 2nd International Conference on Materials Science, Atlantis Press, in: 2nd Int. Conf. Mater. Sci. Atl. Press Mach. Energy Eng., 2017: pp. 795-798.

[19] Raza, Z.A., Rehman, A., Anwar, F. and Usman, A., Development and antibacterial performance of silver nanoparticles incorporated polydopamine-polyester-knitted fabric, Bull. Mater. Sci. 98 (2016) 391-396.

[20] P.I. Steve Upstone, Validating UV / Visible Spectrophotometers, Tech. Note. (2012).

[21] AATCC Test Method 66-2008, Wrinkle Recovery of Woven Fabrics: Recovery Angle. AATCC Technical Manual, American Association of Textile Chemists and Colorists, Research Triangle Park, NC, 91-94, (2010).

[22] I.S. Tania, M. Ali, R.H. Bhuiyan, Experimental Study on Dyeing Performance and Antibacterial Activity of Silver Nanoparticle-Immobilized Cotton Woven Fabric, Autex Res. J. 21 (2020) 1-7. https://doi.org/10.2478/aut-2019-0074.

[23] T. Theivasanthi, M. Alagar, Electrolytic synthesis and characterization of silver nanopowder, Nano Biomed. Eng. (2012). https://doi.org/10.5101/nbe.v4i2.p58-65.

[24] K. Jyoti, M. Baunthiyal, A. Singh, Characterization of silver nanoparticles synthesized using Urtica dioica Linn. leaves and their synergistic effects with antibiotics, J. Radiat. Res. Appl. Sci. (2016). https://doi.org/10.1016/j.jrras.2015.10.002.

[25] I.S. Tania, S.M. M Kabir, M.Z. Uddin, Effects of Resin Treatments on the Quality of Cotton Fabric Dyed with Reactive Dye, Fibres Text. East. Eur. 26 (2018) 102-107. https://doi.org/10.5604/01.3001.0010.7804. 
[26] M.E. Yazdanshenas, M. Shateri-Khalilabad, In situ synthesis of silver nanoparticles on alkali-treated cotton fabrics, J. Ind. Text. (2013). https://doi.org/10.1177/1528083712444297.

\section{Figures}

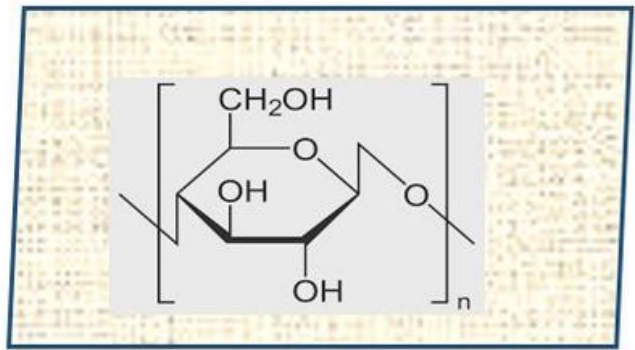

Cotton fabric
Keep into the dopamine solution at $\mathrm{P}^{\mathrm{H}} 8.5$ for 24 hours

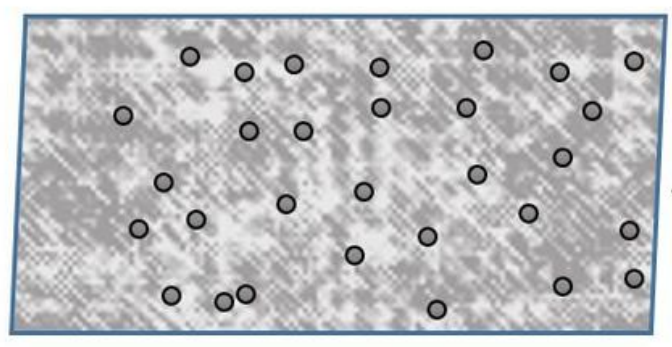

D.Nano Ag ( ) Eoating
Continuous stirring at $30^{\circ} \mathrm{C}$ for 8 hours

Dopamine causes the reduction of $\mathrm{Ag}^{(+)}$

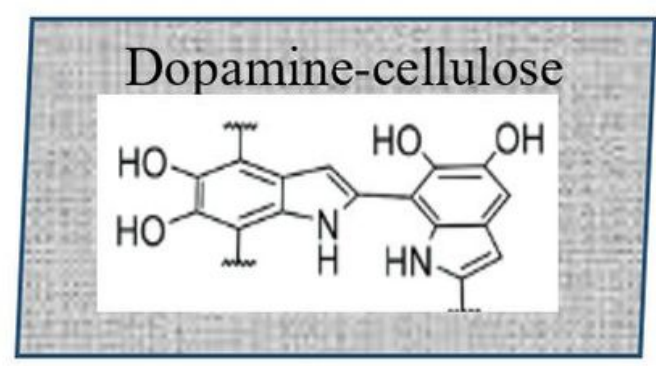

Immerge into $10 \mathrm{mM}$ $\mathrm{AgNO}_{3}$

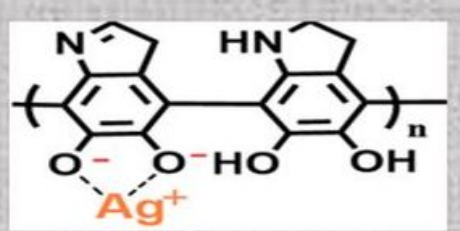

\section{Figure 1}

The schematic diagram for the in-situ formation of Ag nanoparticles

(a)

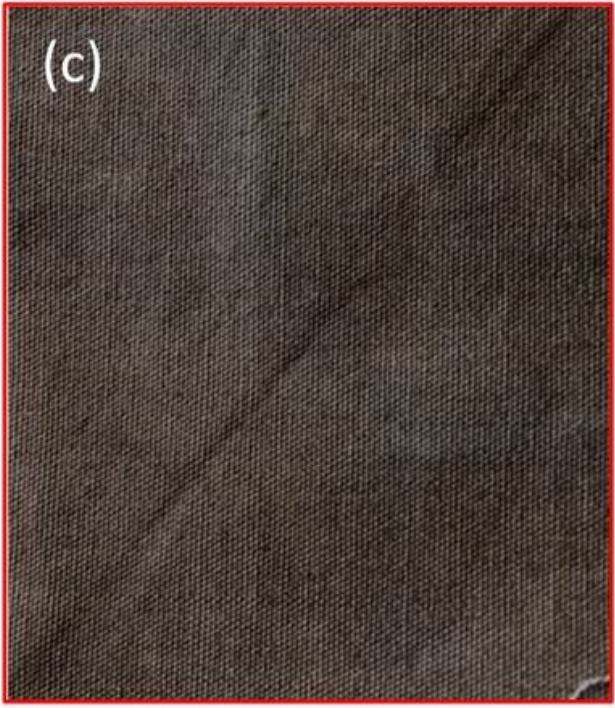


Figure 2

Photographic image of untreated, Dopamine modified, and nano-Ag deposited cotton fabric (D.Nano Ag)
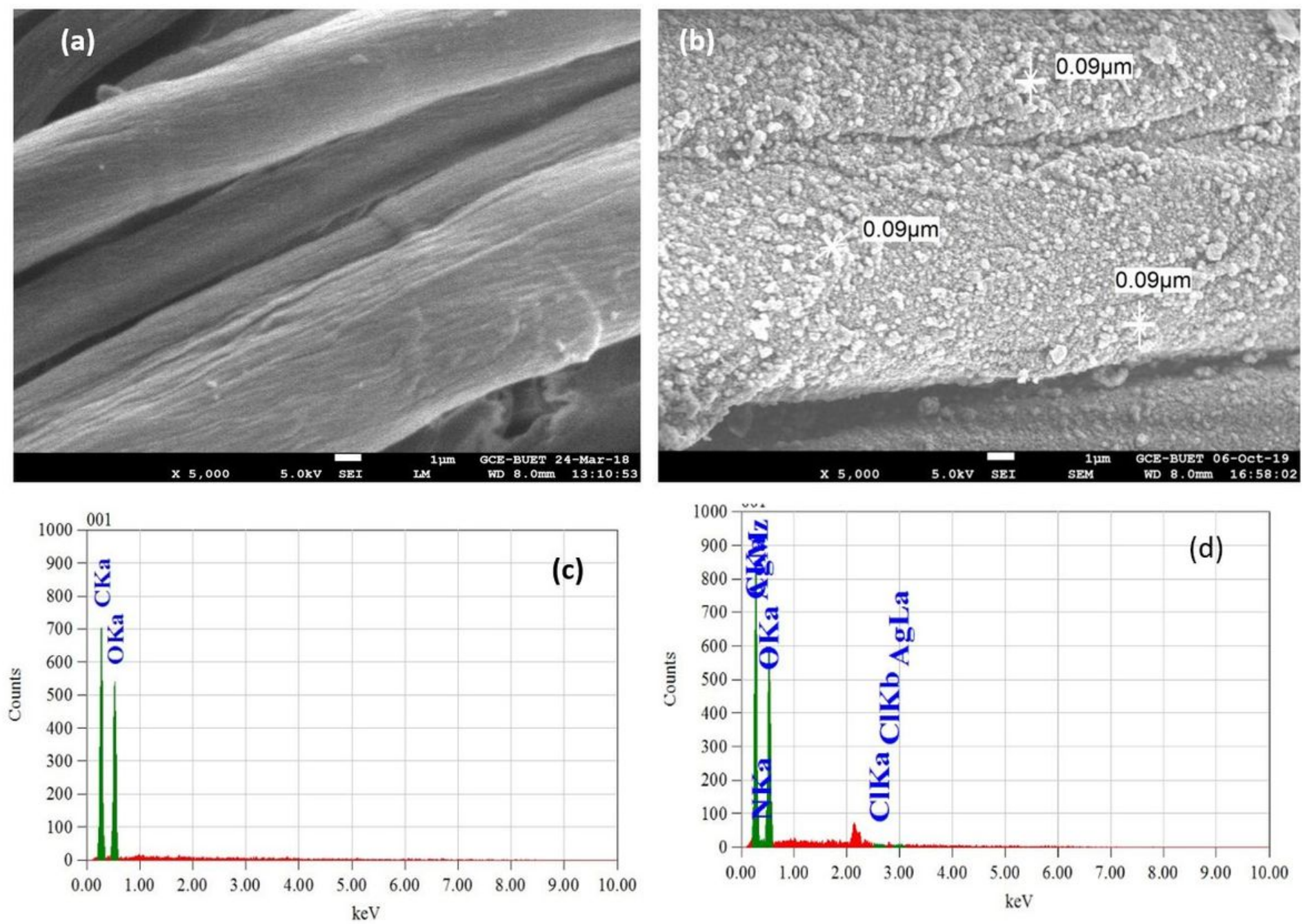

Figure 3

SEM images of (a) untreated, and (b) nano-Ag deposited fabric; EDS image of (c) untreated, and (d) NanoAg deposited fabric 


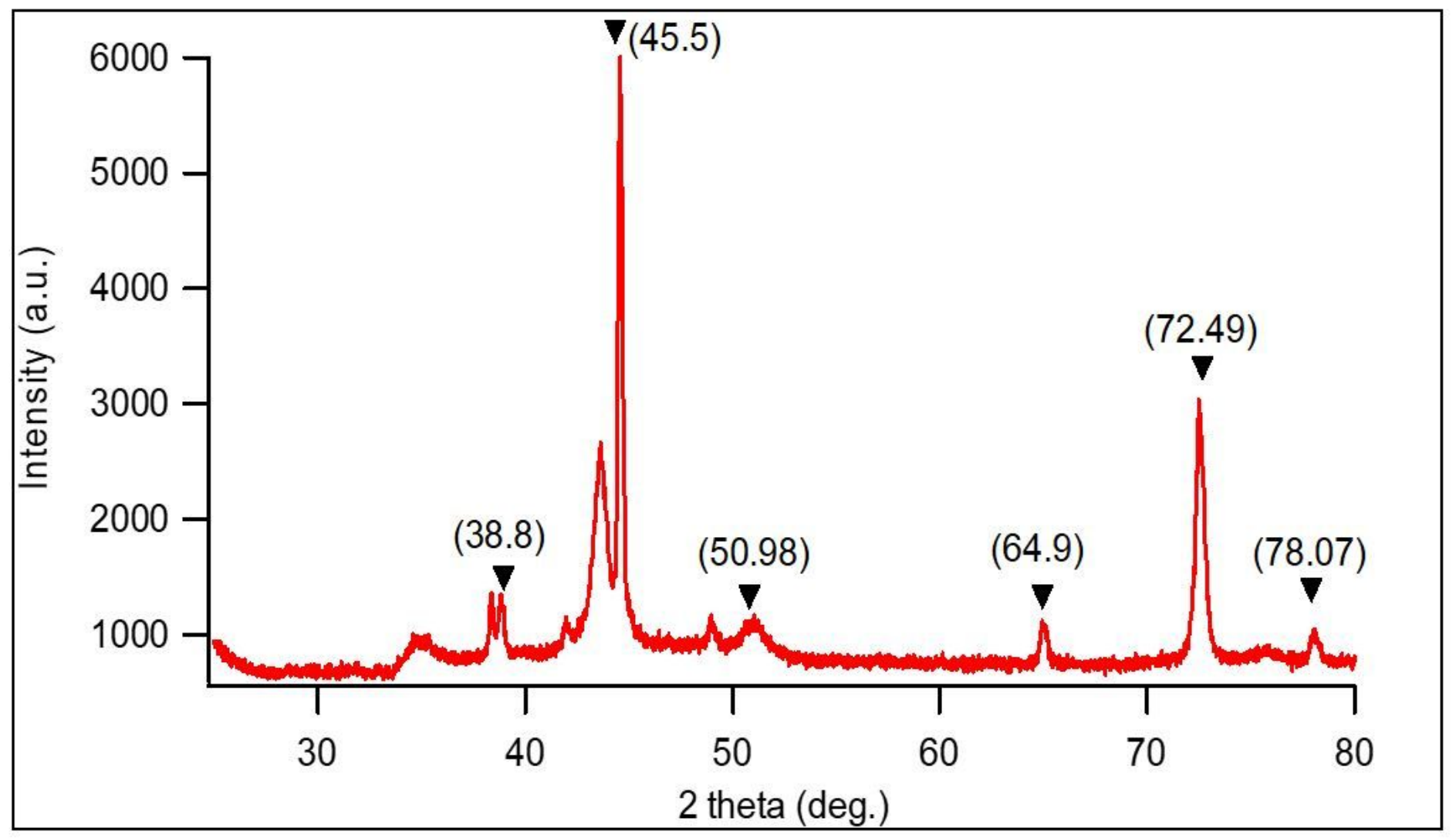

Figure 4

XRD pattern of nano-Ag deposited fabric

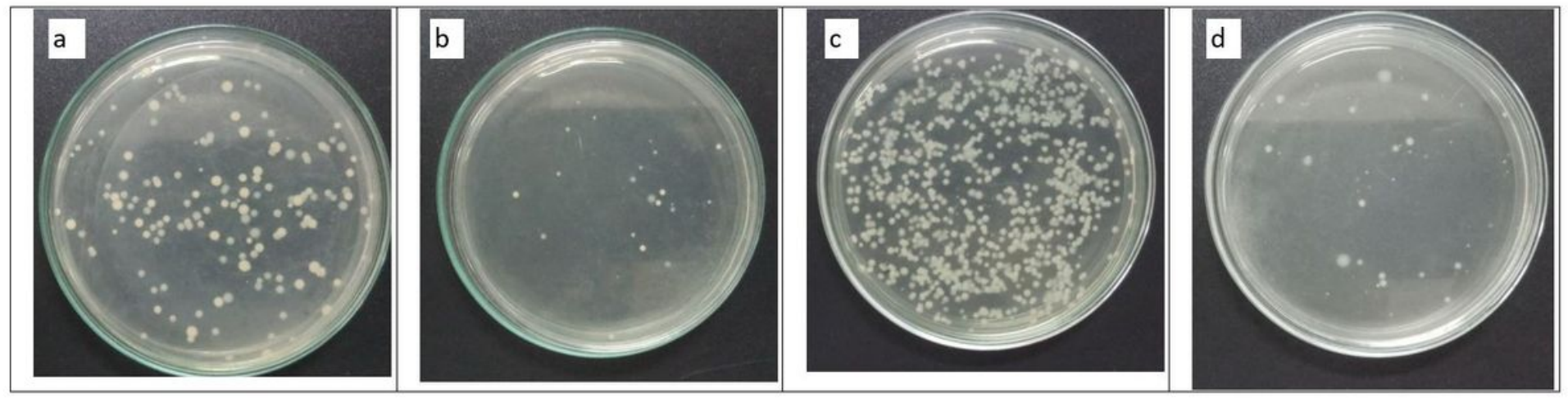

Figure 5

Bacterial growth disk image of (a) untreated \& (b) Nano Ag deposited fabric against S.aureus; (c) untreated \& (d) Nano Ag deposited against E.coli. 


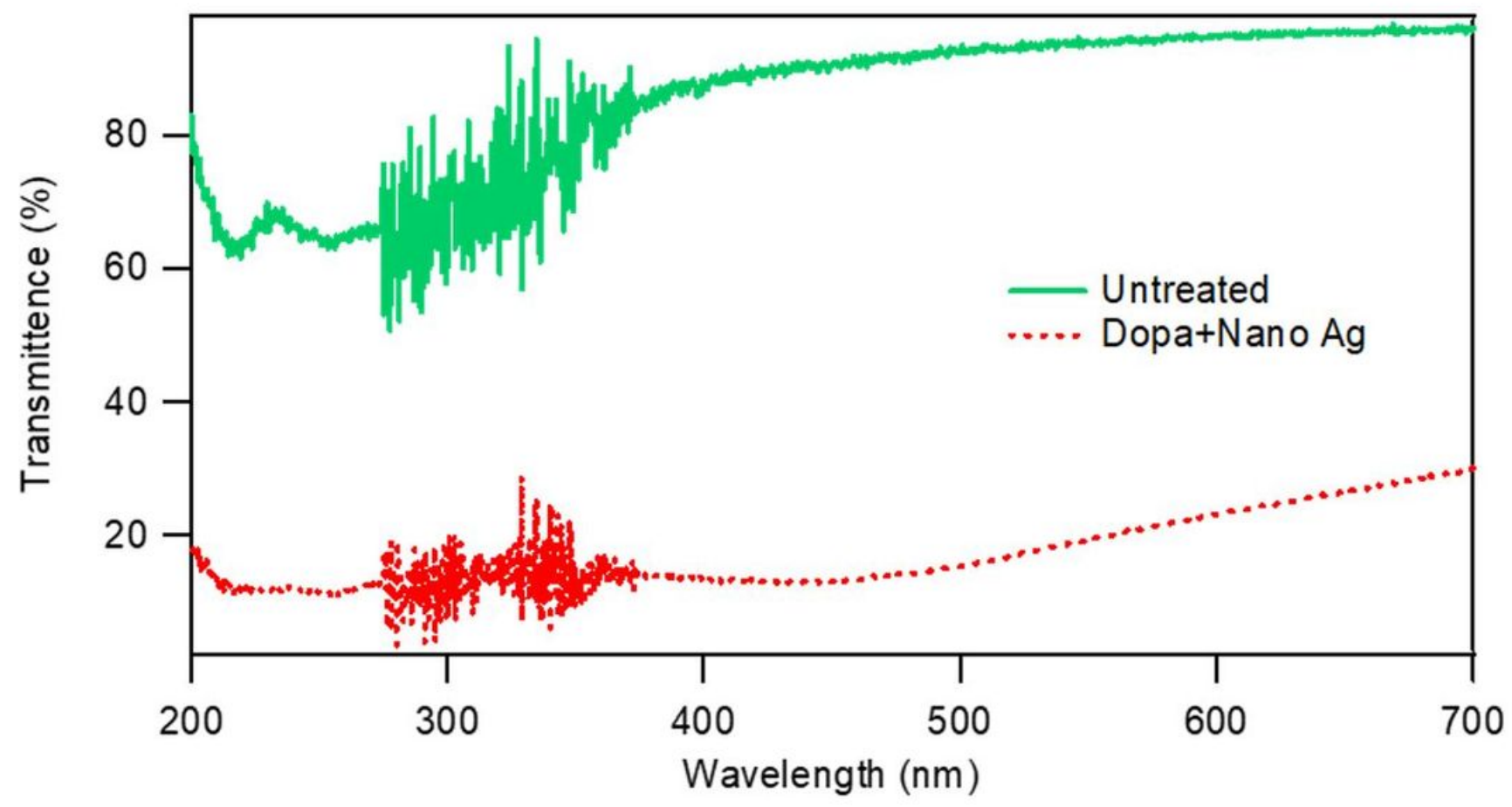

Figure 6

UV transmittance curve of untreated and nano-Ag deposited fabric (Dopa+Nano Ag)

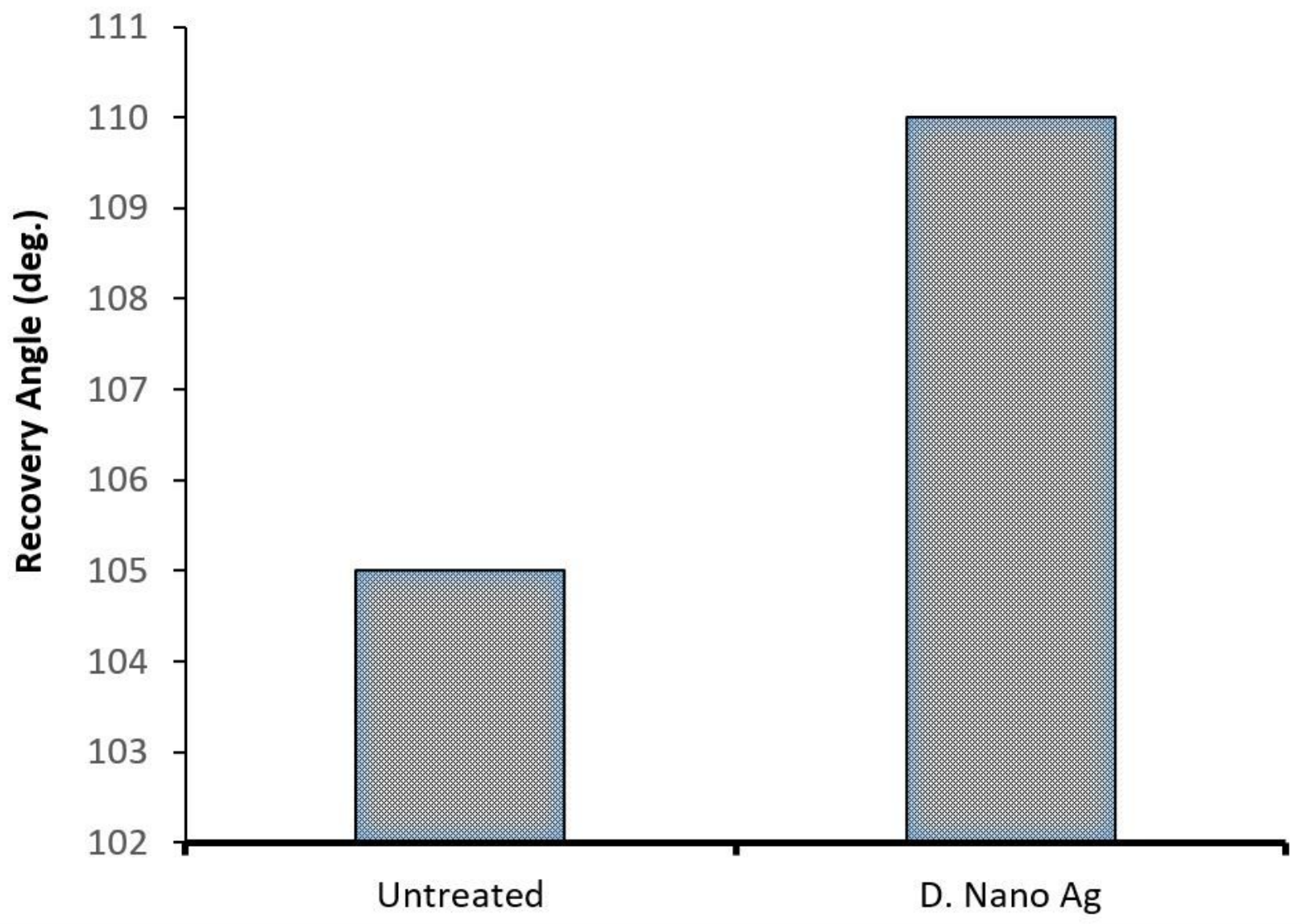


Figure 7

UV transmittance curve of untreated and nano-Ag deposited fabric (Dopa+Nano Ag) 